\title{
Bidirectional Isolated Dual-Active-Bridge (DAB) DC-DC Converters Using 1.2-kV 400-A SiC-MOSFET Dual Modules
}

\author{
Hirofumi Akagi, Shin-ichi Kinouchi, and Yuji Miyazaki
}

\begin{abstract}
This paper describes the $750-\mathrm{Vdc}, 100-\mathrm{kW}, 20$ $\mathrm{kHz}$ bidirectional isolated dual-active-bridge (DAB) dcdc converters using four 1.2-kV 400-A SiC-MOSFET dual modules with or without Schottky barrier diodes (SBDs). When no SBD is integrated into each dual module, the conversion efficiency from the dc-input to the dc-output terminals is accurately measured to be $98.0 \%$ at the rated-power (100 $\mathrm{kW}$ ) operation, and the maximum conversion efficiency is as high as $98.8 \%$ at $41-\mathrm{kW}$ operation, excluding the gatedrive and control-circuit losses from the total power loss. The bidirectional isolated DAB dc-dc converters are so flexible that series and/or parallel connections of their individual input and output terminals make it easy to expand the voltage and current ratings for various applications such as the so-called "solid-state transformer" or "power electronic transformer."
\end{abstract}

Index Terms-Bidirectional isolated dc-dc converters, conversion efficiency, dual-active-bridge configuration, $\mathrm{SiC}$ MOSFET modules.

\section{INTRODUCTION}

$\mathrm{B}$ IDIRECTIONAL isolated dc-dc converters have been expected to play an important role in integrating battery energy storage systems into medium-voltage and/or lowvoltage dc power systems. Particular attention has been paid to a bidirectional isolated dc-dc converter combining two single-phase or three-phase full-bridge voltage-source converters with a single-phase or three-phase high-frequency transformer [1].

Fig. 1 shows the basic circuit configuration of the bidir-ectional isolated dc-dc converter based on two single-phase voltage-source converters using eight MOSFETs and anti-parallel diodes as the power switching devices. This kind of dc-dc converter is often referred to as the "dual-ac-

Manuscript received December 10, 2016. This work was supported by Council for Science, Technology and Innovation(CSTI), Cross-ministerial Strategic Innovation Promotion Program (SIP), "Next-generation power electronics" (funding agency: NEDO).

Hirofumi Akagi is with the Department of Electrical and Electronic Engineering, Tokyo Institute of Technology, Tokyo, 152-8552, Japan (e-mail:akagi@ee.titech.ac.jp), Shin-ichi Kinouchi is with Automotive Electronics Development Center, Mitsubishi Electric Corp. Chiyodamachi, Himeji,670-8677, Japan (e-mail: kinouchi.shinichi@bx.MitsubishiElectric. co.jp), and Yuji Miyazaki is with Power Device Works, and Mitsubishi Electric Corporation, Fukuoka, 819-0192, Japan (e-mail: Miyazaki.Yuji@ dx.MitsubishiElectric.co.jp).

Digital Object Identifier 10.24295/CPSSTPEA.2016.00004 tive-bridge $\mathrm{v}(\mathrm{DAB})$ converter." This naming comes from circuit topology [2], while the original naming of the "bidirectional isolated dc-dc converter" comes from functionality. Strictly speaking, this dc-dc converter should be referred to as the "bidirectional isolated DAB dc-dc converter," to identify itself clearly and to avoid confusion.

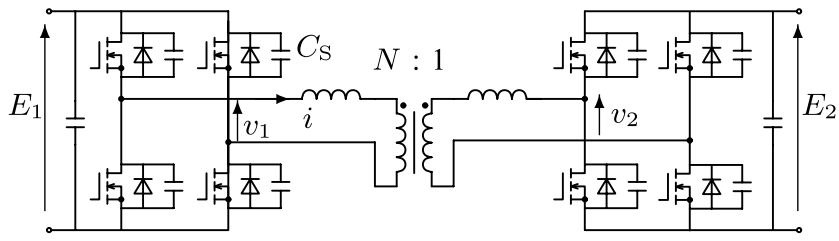

Fig. 1. Bidirectional isolated dual-active-bridge (DAB) dc-dc converter.

The DAB dc-dc converter is symmetrical in circuit topology when the two voltage-source converters are seen upstream and downstream of the high-frequency transformer whose turns ratio is unity $(\mathrm{N}=1)$ in Fig. 1 . The dc-dc converter is characterized by less switching stress on the MOSFETs and diodes, and less ripple voltage/current stress on the dc two capacitors. The reason is that the auxiliary lossless snubber capacitor $C \mathrm{~s}$, connected across each MOSFET, allows the $\mathrm{dc}-\mathrm{dc}$ converter to achieve zero-voltage switching (ZVS). This makes it possible to construct bidirectional isolated dc$\mathrm{dc}$ converters in a range from a few tens to several hundreds of kilowatts, depending strongly on available power devices and their optimal switching frequencies. However, one of the most important research items for putting them into practical use is to improve conversion efficiency at high-frequency operation [3]-[14].

Recently, a significant progress has been made in $\mathrm{SiC}$ (Silicon Carbide) power devices as a result of continuous efforts by research scientists and engineers. This progress has made it possible to fabricate not only discrete SiC-SBDs (Schottky barrier diodes), SiC-JFETs and SiC-MOSFETs but also SiC-MOSFET/SBD modules [15]. Conventional 1.2$\mathrm{kV} \mathrm{Si-IGBT/PND} \mathrm{modules} \mathrm{can} \mathrm{be} \mathrm{replaced} \mathrm{with} \mathrm{emerging}$ 1.2-kV SiC-MOSFET/SBD modules, thus leading to higher conversion efficiencies and/or higher switching frequencies [16], [17].

This paper design, construct, and test two $750-\mathrm{Vdc}, 100-$ $\mathrm{kW}, 20-\mathrm{kHz}$ bidirectional isolated DAB dc-dc converters using four 1.2-kV 400-A SiC-MOSFET dual modules. Note that the "dual module," forming one leg by itself, is referred 
to as the "two-in-one" module in some cases. One dc-dc converter has a Schottky barrier diode (SBD) connected in anti-parallel to each SiC MOSFET, and the other has no SBD connected. The two converters are the same in voltage, current, and operating frequency except that the SiC-MOSFET dual modules have SBDs integrated or not.

Unlike an insulated-gate bipolar transistor (IGBT), any MOSFET, irrespective of Silicon or Silicon Carbide, has the capability of bidirectional current flow as long as a much higher positive voltage than the so-called "threshold voltage" is applied to the gate terminal with respect to the source terminal. Since the MOSFET has no "built-in voltage," it has a lower on-state voltage at small drain currents than does the IGBT. Moreover, the MOSFET has the so-called "body diode" inherent in it. Hence, operating the MOSFET with synchronous-rectification mode makes it possible to remove the anti-parallel SBD from the MOSFET because the body diode acts as the anti-parallel diode during a dead or blanking time. The removal of the anti-parallel SBDs would make a significant contribution to cost reduction from a business point of view.

One objective of this paper is to accurately measure the overall power loss of the $750-\mathrm{Vdc}, 100-\mathrm{kW}, 20-\mathrm{kHz} \mathrm{DAB}$ dc-dc converters using 1.2-kV 400-A SiC-MOSFET dual modules with or without SBDs, excluding the gate-drive and control-circuit power losses. The other is to verify stable operation of the DAB dc-dc converter using SiC-MOSFET dual modules without SBDs in synchronous-rectification mode. Experimental results obtained from the dc-dc converter using SiC-MOSFET dual modules verify that the maximum conversion efficiency from the dc input terminals to the dc output terminals is $98.8 \%$ at $41 \mathrm{~kW}$ and that the conversion efficiency at $100 \mathrm{~kW}$ is $98.0 \%$ with a tolerance of $0.03 \%$.

In the near future, the conversion efficiency will reach higher than $99 \%$ in a broad power range from an extremelylight load to the rated load when the next-generation trenchgate SiC-MOSFET modules and new magnetic materials are available. Finally, this paper provides three possible circuit configurations making series and/or parallel connections of two identical DAB dc-dc converters, intended for expanding their voltage and current ratings.

\section{Operation Of The DAB DC-DC Converter}

Fig. 1 shows a general bidirectional isolated dual-activebridge dc-dc converter suitable for high-power applications [1]-[3]. When the phase-shift control proposed in [1] is applied to the dc-dc converter, the two bridge converters produce two " $180^{\circ}$-conducting" rectangular voltages, $v_{1}$ and $v_{2}$, with a phase difference of $\delta$ and different amplitudes of $E_{1}$ and $E_{2}$, respectively. The dc-output power can be controlled by adjusting the phase-shift angle $\delta$ between $v_{1}$ and $v_{2}$ is given by

$$
P=\frac{E_{1} N E_{2}}{\omega L} \delta\left(1-\frac{|\delta|}{\pi}\right)
$$

Here, $\delta$ takes a positive value when $v_{1}$ leads $v_{2}$ by $\delta, N$ is a voltage ratio of the transformer, $f$ is the switching frequency $(\omega=$ $2 \pi f)$, and

$$
L=L_{\mathrm{A}}+l
$$

where $L$ is the equivalent inductance given by the summation of the four auxiliary inductors and the leakage inductance of the transformer, in which both inductance values are referred to the primary side of the transformer. When $\delta$ takes a positive value, power flow occurs from left to right in Fig. 1. Both bridges 1 and 2 are operated with "synchronous rectification mode" in which an arm current flows through the corresponding MOSFET. Therefore, no current flows through the SBD connected in anti-parallel to the MOSFET under such an ideal condition that no dead time exists in each leg of bridges 1 and 2 .

\section{EXPERIMENTAL SyStem}

\section{A. Circuit Configuration and Conversion Efficiency}

Fig. 2 shows the experimental circuit configuration of the $750-\mathrm{Vdc}, 100-\mathrm{kW}, 20-\mathrm{kHz}$ bidirectional isolated dc$\mathrm{dc}$ converter using 1.2-kV 400-A SiC-MOSFET/SBD dual modules. Note that the MOSFET and SBD power chips designed and fabricated by Mitsubishi Electric were mounted on each dual module. This converter is designed, constructed for accurately measuring the overall power loss from the de input terminals to the dc output terminals. This circuit configuration is characterized by directly connecting the dc output terminals of bridge 2 back to the de input terminals of bridge 1 .

TABLE I summarizes the circuit parameters used in Fig. 2. The dc-dc converter consists of the four $1.2-\mathrm{kV}, 400-\mathrm{A}$ SiCMOSFET/ SBD dual modules, a single-phase $20-\mathrm{kHz}$ transformer with unity voltage ratio, four auxiliary inductors $L_{\mathrm{A}}$, and eight auxiliary snubber capacitors $C_{\mathrm{S}}$. If $3.3-\mathrm{kV} \mathrm{SiC}$ MOSFET modules were available, it would be possible to design, build and test another bidirectional isolated dc-dc converter with a voltage ratio of $N: 1$ in which $N$ is not unity. In the following experiments, however, used are only the $1.2-\mathrm{kV}, 400-\mathrm{A}$ SiC-MOSFET dual modules with or without SBDs. Therefore, a transformer with unity voltage ratio is

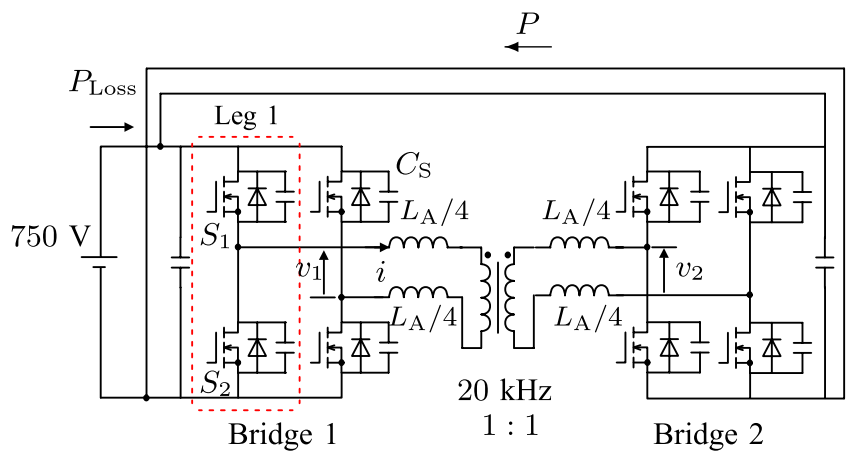

Fig. 2. Experimental circuit using four 1.2-kV 400-A SiC-MOSFET dual modules, each of which has two SBDs integrated. 
used with paying attention to the overall power loss of the dc-dc converter rated at $750 \mathrm{Vdc}, 100 \mathrm{~kW}$, and $20 \mathrm{kHz}$.

TABLE I

Circuit Parameters of the Experimental Circuit Shown in Fig. 2.

\begin{tabular}{lll}
\hline \hline Power rating & & $100 \mathrm{~kW}$ \\
\hline Input/output voltage rating & $E$ & $750 \mathrm{Vdc}$ \\
\hline Switching frequency & $f$ & $20 \mathrm{kHz}$ \\
\hline Auxiliary inductor & $L_{\mathrm{A}}$ & $16.6 \mu \mathrm{H}(37.1 \%)$ \\
\hline Leakage inductance & $l$ & $0.7 \mu \mathrm{H}(1.6 \%)$ \\
\hline Phase shift angle & $\delta$ & $0- \pm 26.6^{\circ}$ \\
\hline Snubber capacitor & $C_{\mathrm{S}}$ & $4.5 \mathrm{nF} / 9 \mathrm{nF}$ \\
\hline Dead time & $T_{\mathrm{D}}$ & $0.6 \mu \mathrm{s} / 0.8 \mu \mathrm{s}$ \\
\hline Transformer core material & & FINEMET* \\
\hline Maximum flux density & & $0.48 \mathrm{~T}$ at $20 \mathrm{kHz}$ \\
\hline Transformer voltage ratio & $1: 1$ \\
\hline \hline
\end{tabular}

* Nano-crystalline soft-magnetic material.

Generally, a university laboratory has the difficulty of providing the $750-\mathrm{Vdc} 100-\mathrm{kW}$ dc power supply and resistive load necessary for this experiment. This difficulty can be solved by actively using the functions of galvanic isolation and unity voltage ratio between the dc input terminals and the dc output terminals. In other words, the dc output terminals of bridge 2 are directly connected to the dc input terminals of bridge 1 , so as to regenerate the output power $P$ to the dc input terminals [4]. As a result, the $750-\mathrm{V}$ dc power supply feeds a small amount of electric power, which corresponds to the overall power loss $P_{\text {Loss }}$. This configuration allows the direct measurement of $P_{\text {Loss, }}$, independent of the measurement of $P$.

The conversion efficiency from the dc input terminals to the dc output terminals, $\eta$ can be calculated by

$$
\eta=\frac{P}{P+P_{\text {Loss }}} .
$$

A digital power analyzer (HIOKI 3390-10) was used to measure $P$ and $P_{\text {Loss }}$ simultaneously and individually. As a result, the accurate conversion efficiency obtained from (3) has a tolerance as small as $0.03 \%$ under such an acceptable assumption that $P_{\text {Loss }}$ is much smaller than $P$. It would be impossible to attain such a small tolerance when the dcinput power and the dc-output power were measured simultaneously and individually even if a high-performance digital power analyzer were used.

\section{B. Design of Auxiliary Snubber Capacitors and Inductors}

As shown in Fig. 2, the auxiliary snubber capacitor $C_{\mathrm{S}}$ is connected across each SiC-MOSFET/SBD in order to reduce both switching loss and overvoltage. Like the equivalent inductor given by (2), the equivalent capacitance $C$ is defined by

$$
C=C_{\mathrm{S}}+C_{\mathrm{ds}},
$$

where $C_{\mathrm{S}}$ is the auxiliary snubber capacitor, and $C_{\mathrm{ds}}$ is the parasitic drain-to-source capacitance across each SiCMOSFET/SBD. The series resonance between the equivalent inductance and the equivalent capacitance $C$ allows the dcdc converter to achieve zero-voltage switching (ZVS).

A tradeoff or compromise exists in selecting the auxiliary inductor $L_{\mathrm{A}}$. As the inductor value is reduced, the phase-shift angle becomes smaller as long as the dc output power $P$ is constant, as seen from (1). This requires a fine adjustment and a high resolution to the phase-shift angle $\delta$ although the inductor size, volume and cost are minimized. Thus, the authors have designed the phase-shift angle $\delta$ to be in a range from $-26.6^{\circ}$ to $26.6^{\circ}$.

\section{Design of an Optimal Dead Time}

The authors of [18] have presented an optimal dead time $T_{\text {DOpt }}$ for minimizing the snubber loss as follows:

$$
T_{\mathrm{DOpt}}=\frac{\pi \sqrt{L C}}{2} .
$$

Equation (5) includes the equivalent capacitance $C$, so that the optimal dead time should be changed, according to the capacitance value of $C_{\mathrm{S}}$. Experimental voltage waveforms allow the authors to set the optimal dead time to $0.6 \mu$ s for $C_{\mathrm{S}}$ $=4.5 \mathrm{nF}$ and to $0.8 \mu \mathrm{s}$ for $C_{\mathrm{S}}=9 \mathrm{nF}$. Under the ZVS operation, the duration of the current flowing through each SBD is shorter than the optimal dead time. Moreover, the duration of the current flowing through the equivalent capacitance $C$ becomes longer as the output power $P$ decreases.

\section{Phase-Shift Control and Synchronous Rectification}

As to the control method for the dc-dc converter, this paper does not use any pulsewidth modulation (PWM) but uses the phase-shift control proposed in [1]. This phase-shift control yields two $180^{\circ}$-conducting rectangular voltages, $v_{1}$ and $v_{2}$, with the same amplitude as $750 \mathrm{~V}$ but with a phaseangle difference of $\delta$, as shown in the voltage waveforms of Fig. 3 . The phase-shift control is characterized by being able to achieve zero-voltage switching in a broad range of 20 to $100 \mathrm{~kW}$, as shown in Fig. 5 later on. However, once a PWM method is used for the dc-dc converter, hard switching happens in all the range of power transfer, so that the switching loss increases.

As mentioned in section II, the use of MOSFET modules make both bridges 1 and 2 operate with synchronous rectification mode. Note that it is impossible to apply synchronous rectification mode to the dual-active-bridge converter using IGBT modules. Synchronous rectification mode allows the "reverse" current to flow in the MOSFET from the source to the drain with a voltage drop across the 
MOSFET as low as $1.1 \mathrm{~V}$ at $150 \mathrm{~A}$, not to flow in the antiparallel Schottky barrier diode (SBD) as long as a positive gate-to-source voltage of $15 \mathrm{~V}$ is applied to the MOSFET. It is well known that the MOSFET is lower in on-resistance than the external SBD and the parasitic or internal pnjunction diode (PND) inherent in the MOSFET. Moreover, the conducting time of each SBD is shorter than an optimal dead time $(=0.6 \mu \mathrm{s})$ in Fig. 2 , which is much shorter than a period of time of $20 \mathrm{kHz}(=50 \mu \mathrm{s})$.

\section{WHEN THE 1.2-KV 400-A SiC-MOSFET DuAL Modules With SBDs ARE UsED}

\section{A. Experimental Waveforms, Overall Power Loss, and Conversion Efficiency}

Fig. 3 shows experimental waveforms of the ac terminal voltages appearing across bridges 1 and $2, v_{1}$ and $v_{2}$, respectively, and the ac current flowing at the ac side of bridge $1, i$, at $f=20 \mathrm{kHz}$ when $C_{\mathrm{S}}=4.5 \mathrm{nF}$ and $T_{\text {Dopt }}=0.6 \mu$ s. Fig. 3 (a) presents those at the rated-power $(P=100 \mathrm{~kW})$ operation, where the waveform of $v_{1}$ leads that of $v_{2}$ by $26.6^{\circ}$. This means that power flow occurs from bridge 1 to bridge 2 . The peak voltage appearing in the waveforms of $v_{1}$ and $v_{2}$ is lower than $950 \mathrm{~V}$, which is within an acceptable level because of using the 1.2-kV SiC modules in Fig. 2. Fig. 3 (b) and Fig. 3(c) are in the cases of $P=30 \mathrm{~kW}$ and $P=10 \mathrm{~kW}$, respectively.

Fig. 4 plots overall conversion efficiencies $\eta$, calculated from (3), with operating frequencies of $f=20 \mathrm{kHz}$ and 10 $\mathrm{kHz}$ when $C_{\mathrm{S}}=4.5 \mathrm{nF}$ and $T_{\mathrm{DOpt}}=0.6 \mu \mathrm{s}$. The maximum conversion efficiency $\eta_{\max }$ is $98.7 \%$ at $P=42.0 \mathrm{~kW}$, and the conversion efficiency at $P=100 \mathrm{~kW}$ is $97.9 \%$ during the 20 $\mathrm{kHz}$ operation.

Fig. 5 plots overall power losses $P_{\text {Loss }}$ under the same conditions as those in Fig. 4. In the ZVS (zero-voltage-switching) region ranging from 20 to $100 \mathrm{~kW}$, the power loss decreases as the output power decreases. In the incomplete-ZVS region ranging from 0 to $20 \mathrm{~kW}$, however, the power loss increases as the output power decreases. This interesting trend comes from an increase in the "power loss" caused by incomplete ZVS.

Fig. 6 and Fig. 7 plot overall conversion efficiencies and overall power losses at $f=20 \mathrm{kHz}$ and $10 \mathrm{kHz}$ when $C_{\mathrm{S}}=9 \mathrm{nF}$ and $T_{\text {DOpt }}=0.8 \mu$ s. The incomplete ZVS region expands into a range from 0 to $26 \mathrm{~kW}$ because the snubber capacitor is larger in capacitance value than that in Fig. 5. The overall power loss at $P=0$ increases from $862 \mathrm{~W}$ in Fig. 5 to $1210 \mathrm{~W}$ in Fig. 7 because the snubber loss increases as the snubber capacitor $C_{\mathrm{S}}$ becomes larger. On the other hand, the overall power loss at $P=$ $100 \mathrm{~kW}$ decreases from $2136 \mathrm{~W}$ to $2027 \mathrm{~W}$ [19].

\section{B. Comparison With a DAB DC-DC Converter Using Four Si-IGBT/PND Dual Modules}

TABLE II summarizes comparisons between the 750$\mathrm{Vdc}, 100-\mathrm{kW}, 20-\mathrm{kHz}$ dc-dc converter using the $1.2-\mathrm{kV}$ 400-A SiC-MOSFET/SBD dual modules [19] and the 750Vdc, $60-\mathrm{kW}, 4-\mathrm{kHz}$ dc-dc converter using 1.2-kV 300-A Si-

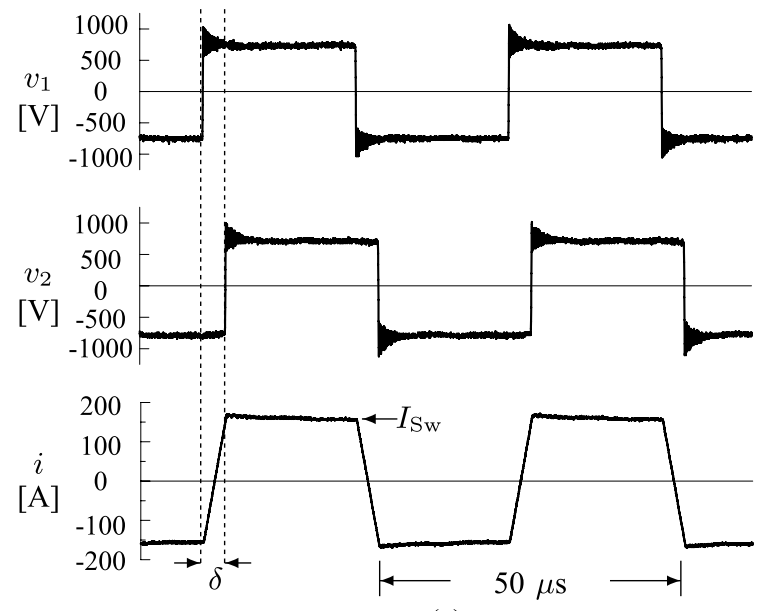

(a)
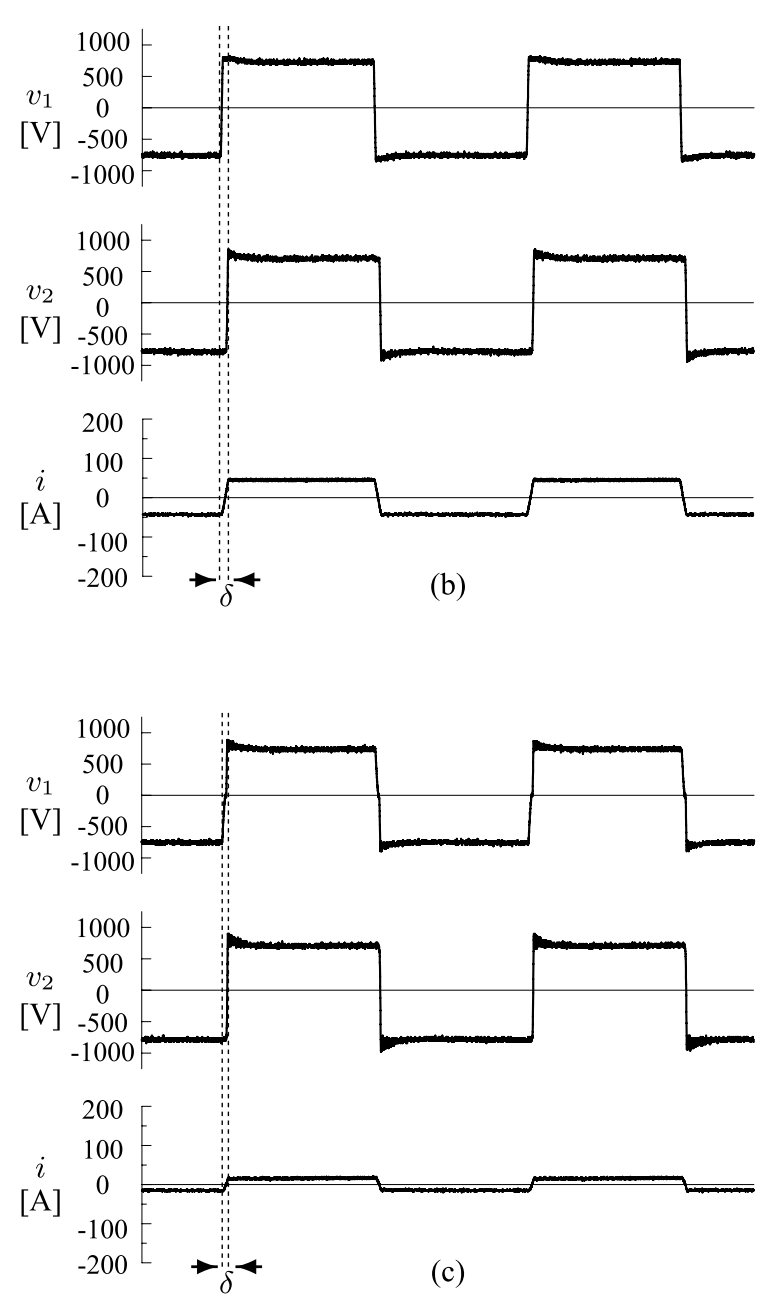

Fig. 3. Experimental waveforms when $f=20 \mathrm{kHz}, C_{\mathrm{S}}=4.5 \mathrm{nF}$ and $T_{\text {Dopt }}=$ $0.6 \mu$ s. (a) $P=100 \mathrm{~kW}$ and $\delta=26.6^{\circ}$. (b) $P=30 \mathrm{~kW}$ and $\delta=7.0^{\circ}$. (c) $P=10$ $\mathrm{kW}$ and $\delta=1.5^{\circ}$.

IGBT/PND dual modules [20]. The two power ratings are not the same because the Si module is different in current rating from the $\mathrm{SiC}$ module. Moreover, the two operating frequencies are not the same because it would be impractical to operate the dc-dc converter using the Si modules at 20 $\mathrm{kHz}$ in terms of increased switching loss. However, note that 


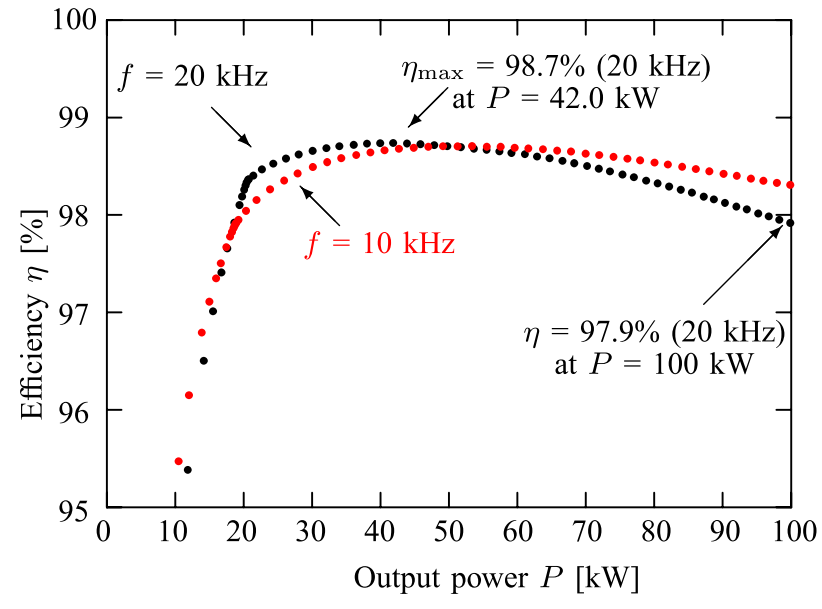

Fig. 4. Conversion efficiency when $C_{\mathrm{S}}=4.5 \mathrm{nF}$ and $T_{\mathrm{D}}=0.6 \mu \mathrm{s}$.

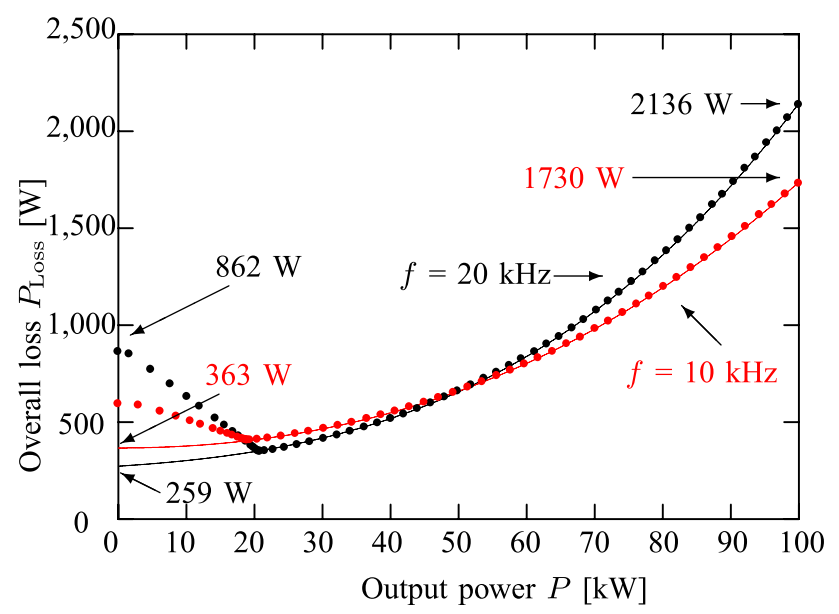

Fig. 5. Measured overall power loss when $C_{\mathrm{S}}=4.5 \mathrm{nF}$ and $T_{\mathrm{D}}=0.6 \mu \mathrm{s}$.

the $\mathrm{SiC}$ module adopts the same packaging in size, shape, and terminal/pin arrangement as the Si module does. A main reason for having the same packaging in appearance is to make it easy for power electronics engineers to replace the Si module with the SiC module.

TABLE II concludes that the use of the $\mathrm{SiC}$ modules makes the maximum efficiency higher by $0.9 \%$ and the rated-power efficiency higher by $1.0 \%$ than the use of the $\mathrm{Si}$

TABLE II

Comparison Between the Two DAB DC-DC Converters Using SiC-MOSFET/SBD AND Si-IGBT/PND Modules.

\begin{tabular}{lcc}
\hline \hline Power module & $\begin{array}{c}1.2-\mathrm{kV}, 400-\mathrm{A} \\
\text { SiC-MOSFET/SBD }\end{array}$ & $\begin{array}{c}1.2-\mathrm{kV}, 300-\mathrm{A} \\
\text { Si-IGBT/PND }\end{array}$ \\
\hline Power rating & $100 \mathrm{~kW}$ & $60 \mathrm{~kW}$ \\
Input/output voltage rating & $750 \mathrm{Vdc}$ & $750 \mathrm{Vdc}$ \\
Switching frequency & $20 \mathrm{kHz}$ & $4 \mathrm{kHz}$ \\
Snubber capacitor & $4.5 \mathrm{nF}$ & $10 \mathrm{nF}$ \\
Maximum efficiency & $98.7 \%$ & $97.8 \%$ \\
Rated power efficiency & $97.9 \%$ & $96.9 \%$ \\
\hline \hline
\end{tabular}

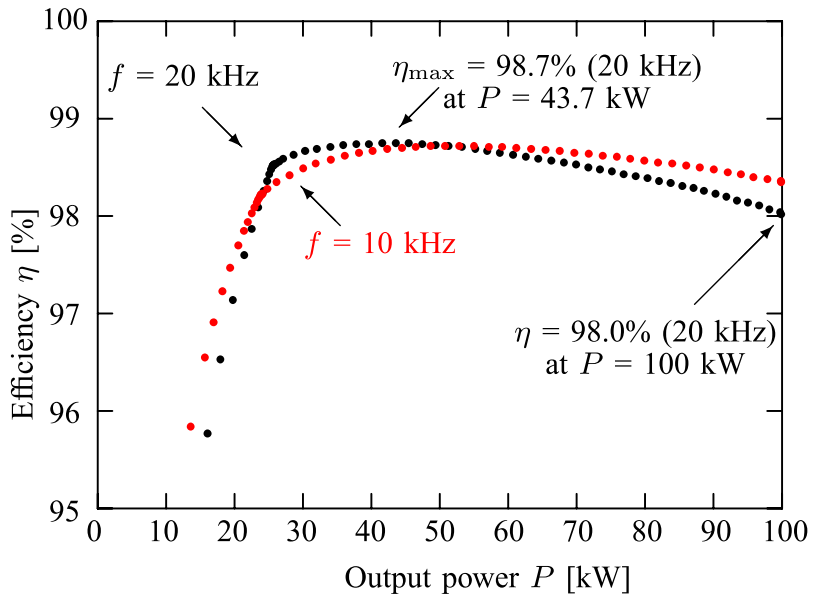

Fig. 6. Conversion efficiency when $C_{\mathrm{S}}=9 \mathrm{nF}$ and $T_{\mathrm{D}}=0.8 \mu \mathrm{s}$.

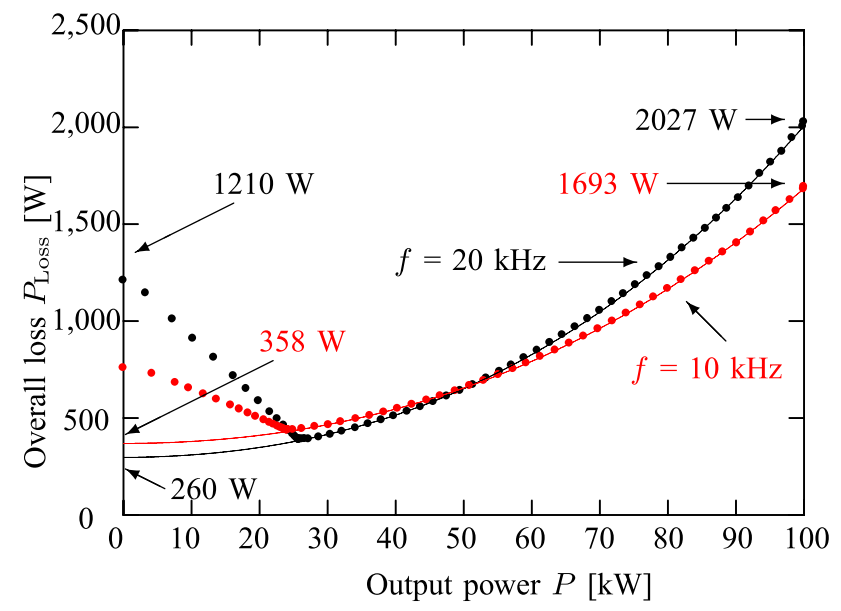

Fig. 7. Measured overall power loss when $C_{\mathrm{S}}=9 \mathrm{nF}$ and $T_{\mathrm{D}}=0.8 \mu \mathrm{s}$.

modules, although the switching frequency is increased from $4 \mathrm{kHz}$ to $20 \mathrm{kHz}$.

\section{Elimination of two SBDs From EACH SiC-MOSFET Dual Module}

\section{A. Experimental System}

Fig. 8 shows the experimental circuit configuration of the $750-\mathrm{Vdc}, 100-\mathrm{kW}, 20-\mathrm{kHz}$ bidirectional isolated dc-dc converter using 1.2-kV 400-A SiC-MOSFET dual modules. Note that the MOSFET power chips designed and fabricated by Mitsubishi Electric were mounted on each dual module. This means that each module has no SBD integrated. TABLE III summarizes the circuit parameters used in the experimental system of Fig. 8. Carefully looking at TABLE I and TABLE III enables one to notice that small differences exist in a few parameters as a result of having tuned to the $1.2-\mathrm{kV} 400-\mathrm{A}$ SiC-MOSFET dual modules used in this experiment. Exactly speaking, the dual modules used for Fig. 2 and Fig. 8 are not the same in SiC-MOSFET chip although the dual modules are the same in voltage and current ratings, 


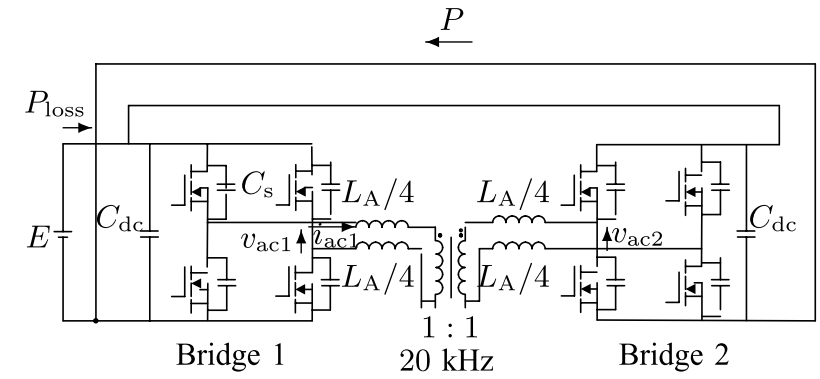

Fig. 8. Experimental circuit using four 1.2-kV 400-A SiC-MOSFET dual modules, each of which has no SBDs integrated.

TABLE III

Circutt Parameters of the Experimental Circuit Shown In Fig. 8.

\begin{tabular}{lcc}
\hline \hline Power rating & & $100 \mathrm{~kW}$ \\
\hline Input/output voltage rating & $E$ & $750 \mathrm{~V} \mathrm{dc}$ \\
\hline Switching frequency & $f$ & $20 \mathrm{kHz}$ \\
\hline Auxiliary inductor & $L_{\mathrm{A}}$ & $16.6 \mu \mathrm{H}$ \\
\hline Leakage inductance & $l$ & $1 \mu \mathrm{H}$ \\
\hline Phase shift angle & $\delta$ & $0- \pm 27.4^{\circ}$ \\
\hline Snubber capacitor & $C_{\mathrm{S}}$ & $4 \mathrm{nF}$ \\
\hline Dead time & $T_{\mathrm{D}}$ & $0.6 \mu \mathrm{s}$ \\
\hline Transformer core material & & FINEMET* \\
\hline Maximum flux density & & $0.48 \mathrm{~T} \mathrm{at} 20 \mathrm{kHz}$ \\
\hline Transformer turns ratio & & $1: 1$ \\
\hline \hline
\end{tabular}

*Nano-crystalline soft-magnetic materidal.

and the SiC-MOSFET chips are integrated into the same packaging in size, shape and terminal/pin arrangement.

\section{B. Experimental Waveforms}

Fig. 9 shows experimental waveforms of the ac terminal voltages appearing across bridges 1 and $2, v_{1}$ and $v_{2}$, respectively, and the ac current flowing at the ac side of bridge $1, i$, at $f=20 \mathrm{kHz}$ when $C_{\mathrm{S}}=4 \mathrm{nF}$ and $T_{\mathrm{D}}=0.6 \mu$ s. Fig. 9(a) presents those at the rated-power $(P=100 \mathrm{~kW})$ operation, where the waveform of $v_{1}$ leads that of $v_{2}$ by $27.4^{\circ}$. This means that power flow occurs from bridge 1 to bridge 2 . The peak voltage appearing in the waveforms of $v_{1}$ and $v_{2}$ is slightly higer than those in Fig. 2. However, it is still within an acceptable level. Fig. 9(b) is in the case of operation at $41 \mathrm{~kW}$ where the maximum conversion efficiency of $98.8 \%$ was achieved, whereas a conversion efficiency was $98.0 \%$ at $100 \mathrm{~kW}[21]$.

TABLE IV summarizes a comparison in conversion efficiency among four different bidirectional isolated DAB dc$\mathrm{dc}$ converters using Si-IGBT modules or SiC-MOSFET modules in the past, the present, and the near future. The next-generation trench-gate SiC-MOSFET modules in terms of structure and performance are under research and development. The combination of the next-generation SiCMOSFET modules with new magnetic materials for highfrequency transformers and auxiliary inductors will make a

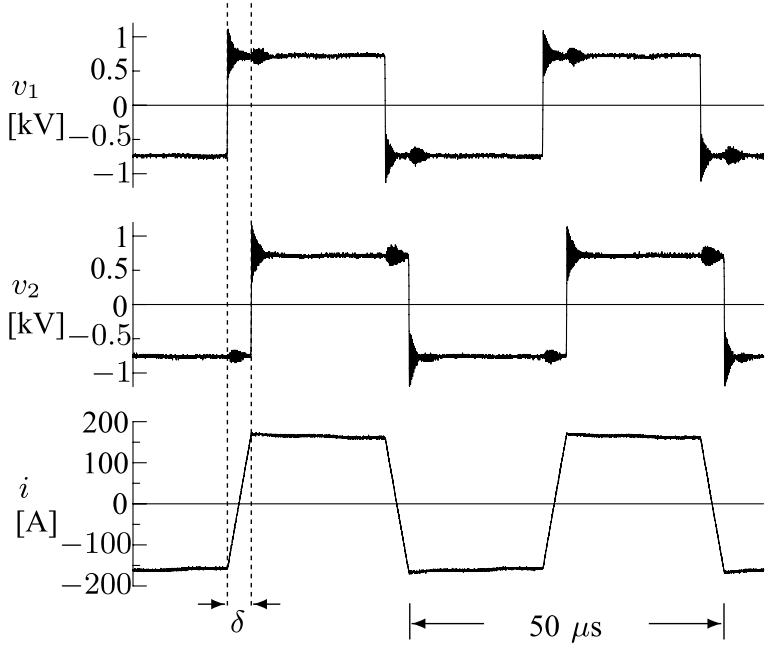

(a)

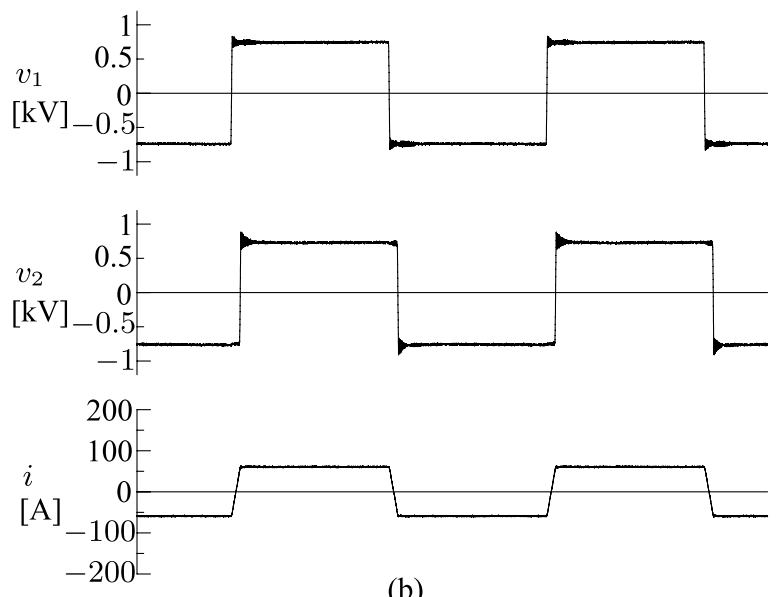

(b)

Fig. 9. Experimental waveforms of the ac terminal voltages of bridges 1 and 2 , $v_{1}$ and $v_{2}$, and the primary current of the transformer, $i$. (a) $P=100 \mathrm{~kW}$ (rated power) at $\delta=27.4^{\circ}$ and (b) $P=41 \mathrm{~kW}$ (maximum efficiency) at $\delta=11^{\circ}$.

significant contribution to reducing the total power loss. As a result, the conversion efficiency of the $750-\mathrm{Vdc} 100-\mathrm{kW} 20-$ $\mathrm{kHz}$ dc-dc converter will reach higher than $99 \%$ in a broad output power range of 5 to $100 \mathrm{~kW}$.

\section{Series and/or Parallel Connections of Bidirectional Isolated DAB DC-DC CONVERTERS}

It is clear from the basic circuit configuration shown in Fig 1 that this DAB dc-dc converter has the capability of galvanic or electric isolation between the input terminals and the output terminals. This capability makes it easy to series and/or parallel connections of multiple DAB dc-dc converters, intended for expanding voltage and/or current ratings.

Fig. 10 to Fig. 12 show three possible circuit configurations making series and/or parallel connections of two DAB dc-dc converters. Fig. 10 shows the circuit configuration making parallel connections of both input terminals and 
TABLE IV

Conversion Efficiency of Bidirectional Isolated DC-DC Converters: Yesterday, Today, And Tomorrow

\begin{tabular}{|c|c|c|c|c|}
\hline Year and Reference & $1992[2]$ & $2007[4]$ & $2016[21]$ & $2020 ?$ \\
\hline Power Switching Devices & $\begin{array}{l}\text { Planar-Gate } \\
\text { Si-IGBTs }\end{array}$ & $\begin{array}{l}\text { Trench-Gate } \\
\text { Si-IGBTs }\end{array}$ & $\begin{array}{c}\text { Planar-Gate } \\
\text { SiC-MOSFETs }\end{array}$ & $\begin{array}{c}\text { Trench-Gate } \\
\text { SiC-MOSFETs }\end{array}$ \\
\hline $\begin{array}{l}\text { Rated Output Power and } \\
\text { Switching Frequency }\end{array}$ & $50 \mathrm{~kW}$ and $50 \mathrm{kHz}$ & $10 \mathrm{~kW}$ and $20 \mathrm{kHz}$ & $100 \mathrm{~kW}$ and $20 \mathrm{kHz}$ & $100 \mathrm{~kW}$ and $20 \mathrm{kHz}$ \\
\hline $\begin{array}{l}\text { Magentic Materials Used for } \\
\text { Transformers }\end{array}$ & Ferrite & FINEMET & FINEMET & New Materials? \\
\hline $\begin{array}{l}\text { Conversion Efficiency from } \\
\text { DC Input to DC Output }\end{array}$ & Below 90\% & $\begin{array}{l}96.8 \% \text { at } 10 \mathrm{~kW} \\
97.4 \% \text { at } 3.8 \mathrm{~kW}\end{array}$ & $\begin{array}{c}98.0 \% \text { at } 100 \mathrm{~kW} \\
98.8 \% \text { at } 41 \mathrm{~kW}\end{array}$ & Over $99 \%$ \\
\hline
\end{tabular}

The term "FINEMET" is a trade name that means a nano-crystalline soft-magnetic material.

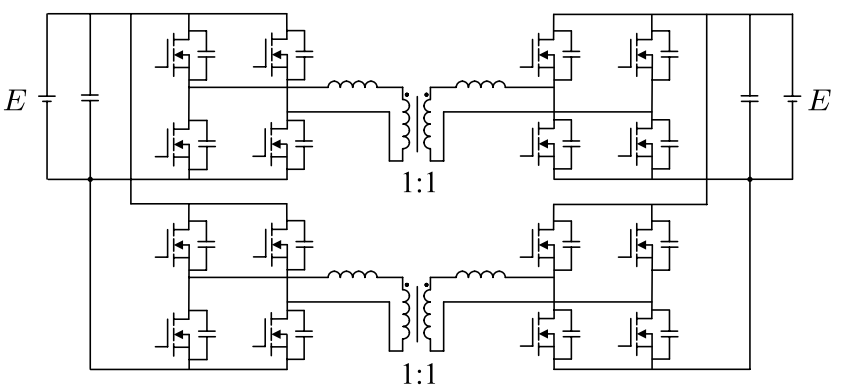

Fig. 10. Input-parallel output-parallel isolated dc-dc converter.

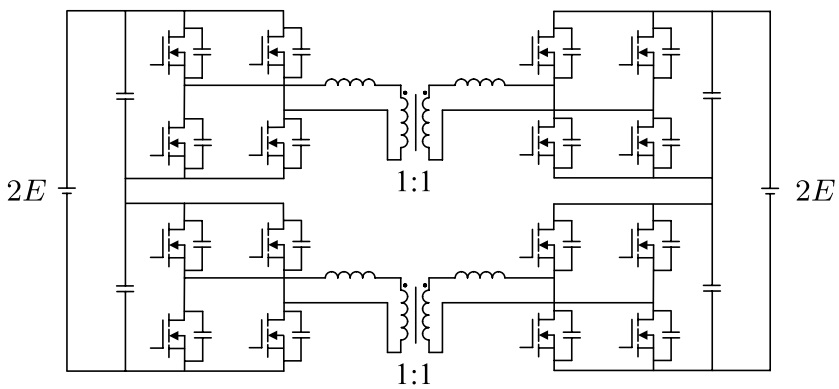

Fig. 11. Input-series output-series isolated dc-dc converter.

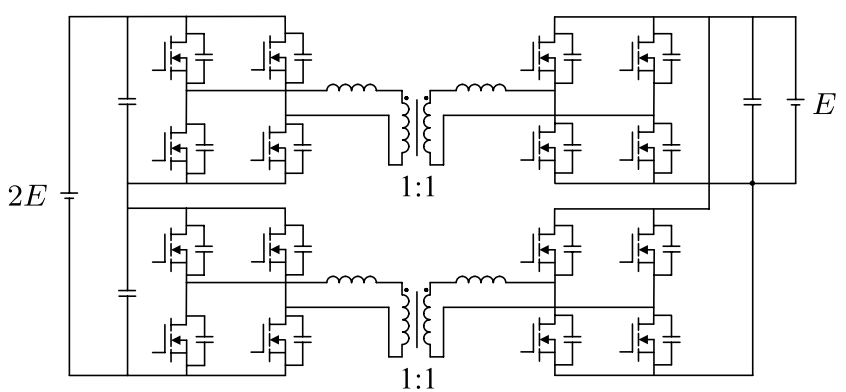

Fig. 12. Input-series output-parallel isolated dc-dc converter.

output terminals. This parallel connections make no circulating current flow between the two dc-dc converters. Therefore, no concern is provided to current sharing between the two.

Fig. 11 shows the circuit configuration making series connections of both input terminals and output terminals. Unlike the parallel connections shown in Fig. 10, the series connections take care of individual voltage balancing in either dc input terminals or dc output terminals although no attention is paid to current balancing.
Fig. 12 shows the circuit configuration making the series connection of the input terminals and the parallel connection of the output terminals. This configuration is so interesting that the dc voltage at the input terminals can be stepped down by half at the output terminals although all the SiCMOSFET modules have the same voltage rating and the two transformers have unity turns ratio. Moreover, any concern is provided to neither current sharing nor voltage balancing.

\section{CONCLUSION}

This paper has designed, built, and tested two 750-Vdc, $100-\mathrm{kW}, 20-\mathrm{kHz}$ bidirectional isolated dual-active-bridge (DAB) dc-dc converters using four $1.2-\mathrm{kV}, 400-\mathrm{A} \mathrm{SiC}-$ MOSFET dual modules with or without SBDs. When the $1.2-\mathrm{kV}, 400-\mathrm{A}$ SiC-MOSFET dual modules without SBDs are used, the maximum conversion efficiency from the dcinput terminals to the dc-output terminals is as high as $98.8 \%$ at $41 \mathrm{~kW}$, and $98.0 \%$ at $100 \mathrm{~kW}$, which are calculated from the accurately-measured overall power loss excluding gatedrive and control circuit losses.

When the next-generation trench-gate SiC-MOSFET modules come across, the conversion efficiency of a welldesigned DAB dc-dc converter is expected to be higher than $99 \%$ in a broad power range, even at the rated power.

Series and/or parallel connections of multiple DAB dc-dc converters would make it easy to expand the voltage and/or current ratings as if the converter were operating as a single high-power DAB dc-dc converter. In particular, the inputseries and output-parallel connections show considerable promise as a dc-dc converter for medium-voltage highpower battery energy storage systems and an interface circuit between two dc power networks with different dc voltages.

\section{REFERENCES}

[1] R. W. De Doncker, D. M. Divan, and M. H. Kheraluwala, "A threephase soft-switched high-power-density dc/dc converter for high power applications," IEEE Trans. Ind. Appl., vol. 27, no. 1, pp. 63-73, Jan./Feb. 1991

[2] M. H. Kheraluwala, R. W. Gascoigne, D. M. Divan, and E. D. Baumann, "Performance characterization of a high-power dual active bridge dctodc converter," IEEE Trans. Ind. Appl., vol. 28, no. 6, pp. 1294-1301, Nov./Dec. 1992.

[3] R. L Steigerwald, R. W. De Doncker, and M. H. Kheraluwala, "A comparison of high-power dc-dc soft-switched converter topologies," IEEE Trans. Ind. Appl., vol. 32, no. 5, pp. 1139-1145, 
Sept./Oct. 1996.

[4] S. Inoue and H. Akagi, "A bidirectional isolated dc-dc converter as a core circuit of the next-generation medium-voltage power conversion system," IEEE Trans. Ind. Appl., vol. 22, no. 2, pp. 535-542, Mar. 2007

[5] S. Inoue and H. Akagi, "A bidirectional dc-dc converter for an energy storage system with galvanic isolation," IEEE Trans. Power Electron., vol. 22, no. 6, pp. 2299-2306, Nov. 2007.

[6] N. M. L. Tan, S. Inoue, A. Kobayashi, and H. Akagi, "Voltage balancing of a $320-\mathrm{V}, 12-\mathrm{F}$ electric double-layer capacitor bank combined with a $10-\mathrm{kW}$ bidirectional isolated dc-dc converter," IEEE Trans. Power Electron., vol. 23, no. 6, pp. 2755-2765, Nov. 2008.

[7] C. Zhao, S. D. Round, and J. W. Kolar "An isolated threeport bidirectional dc-dc converter with decoupled power flow management," IEEE Trans. Power Electron., vol. 23, no. 5, pp. 2443-2453, Sept. 2008.

[8] H. Bai and C. Mi, "Eliminate reactive power and increase system efficiency of isolated bidirectional dual-active-bridge dc-dc converters using novel dual-phase-shift control," IEEE Trans. Power Electron., vol. 23, no. 6, pp. 2905-2914, Nov. 2008.

[9] G. G. Oggier, G. O. Garc'1a, and A. R. Oliva, "Switching control strategy to minimize dual active bridge converter losses," IEEE Trans. Power Electron., vol. 24, no. 7, pp. 1826-1838, July 2009.

[10] H. Zhou and A. M. Khambadkone, "Hybrid modulation for dualactive-bridge bidirectional converter with extended power range for ultracapacitor application," IEEE Trans. Ind. Appl., vol. 45, no. 4, pp. 1434-1442, Jul./Aug. 2009.

[11] F. Krismer and J. W. Kolar, "Accurate power loss model derivation of a high-current dual active bridge converter for an automotive application," IEEE Trans. Ind. Electron., vol. 57, no. 3, pp. 881-891, Mar. 2010.

[12] G. Guidi, M. Pavlovsky, A. Kawamura, T. Imakubo, and Y. Sasaki, "Improvement of light load efficiency of dual active bridge dc-dc converter by using dual leakage transformer and variable frequency," in Proc. IEEE ECCE, Sept. 2010, pp. 830-837.

[13] N. M. L. Tan, T. Abe, and H. Akagi, "Design and performance of a bidirectional isolated dc-dc converter for a battery energy storage system," IEEE Trans. Power Electron., vol. 27, no. 3, pp. 1237 1248, Mar. 2012.

[14] R. T. Naayagi, A. J. Forsyth, and R. Shuttleworth, "High-power bidirectional dc-dc converter for aerospace applications," IEEE Trans. Power Electron., vol. 27, no. 11, pp. 4366-4379, Nov. 2012.

[15] R. T. Wood and T. E. Salem, "Evaluation of a 1200-V, 800-A allSiC dual module," IEEE Trans. Power Electron., vol. 26, no. 9, pp. 4366-4379, Sept. 2011.

[16] K. Shirabe, M. Swamy, J. Kan, M. Hisatsune, M. Das, R. Callanan, and $\mathrm{H}$. Lin, "Design of $400 \mathrm{~V}$ class inverter drive using SiC 6-in-1 power module," in Proc. IEEE ECCE, Sep. 2013, pp. 2363-2370.

[17] G. Wang, F. Wang, G. Magai, Y. Lei, A. Huang, and M. Das, "Performance comparison of 1200V 100A SiC MOSFET and 1200V 100A Silicon IGBT," in Proc. IEEE ECCE, Sep. 2013, pp. 32303234.

[18] N. M. L. Tan, T. Abe, and H. Akagi, "Experimental discussions on operating frequencies of a bidirectional isolated dc-dc converter for a battery energy storage system," in Proc. IEEE ECCE, Sep. 2013, pp. 2333-2340.

[19] H. Akagi, T. Yamagishi, N. Tan, S. Kinouchi, Y. Miyazaki, and M.Koyama, "Power-loss breakdown of a $750-\mathrm{V} 100-\mathrm{kW} 20-\mathrm{kHz}$ bidirectional isolated dc-dc converter using SiC-MOSFET/SBD dual modules," IEEE Trans. Ind. Appl., vol. 51, no. 1, pp. 420-4428, Jan./
Feb. 2015

[20] T. Chocktaweechock, K. Hasegawa, and H. Akagi: "System design and experimental verification of a $750-\mathrm{V}, 60-\mathrm{kW}, 4-\mathrm{kHz}$ bidirectional isolated dc-dc converter," in Proc. IEEJ IAS Annual Meeting, Aug. 2012.

[21] H. Hisamochi, H. Akagi, S. Kinouchi, and Y. Miyazaki, "Enhansment of power conversion efficiency in a low-power range of a bidirectional isolated dc-dc converter by intermittent operation," IEEJ Trans. Ind. Appl., vol. 137, no. 7, pp. 501-508, July 2016. (in Japanese)

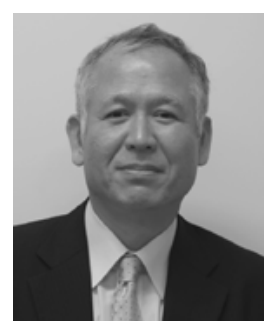

Hirofumi Akagi was born in Okayama, Japan, in 1951 . He received the Ph. D. degree in electrical engineering from the Tokyo Institute of Technology, Tokyo, Japan, in 1979. Since 2000, he has been Professor in the department of electrical and electronic engineering at the Tokyo Institute of Technology. Prior to it, he was with Nagaoka University of Technology, Nagaoka, Japan, and Okayama University, Okayama, Japan.

His research interests include power conversion systems and its applications to industry, transportation, and utility. He has authored and coauthored some 120 IEEE Journals/Transactions papers.

Dr. Akagi has received six IEEE Transactions Prize Paper Awards and 14 IEEE Industry Applications Society (IAS) Committee Prize Paper Awards. $\mathrm{He}$ is the recipient of the 2001 IEEE William E. Newell Power Electronics Award, the 2004 IEEE IAS Outstanding Achievement Award, the 2008 IEEE Richard H. Kaufmann Technical Field Award, and the 2012 IEEE PES Nari Hingorani Custom Power Award. He was elected as an IEEE Fellow in 1996.

Dr. Akagi served as the President of the IEEE Power Electronics Society during 2007-2008. Since 2015, he has been serving as the IEEE Division II Director.

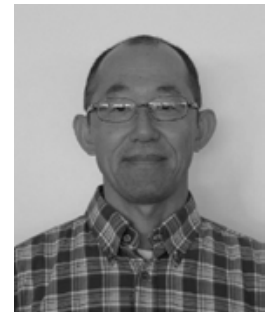

Shin-ichi Kinouchi was born in Japan in 1962 . $\mathrm{He}$ received the B. S. and M. S. degrees in physics from the University of Hokkaido, Sapporo, Japan, in 1986 and 1988, respectively. Since 1988, he has been working for Mitsubishi Electric Company, where he has been engaged in research and development of semiconductor materials, and then power devices and its applications. His research interests include $\mathrm{SiC}$ power devices and packaging.

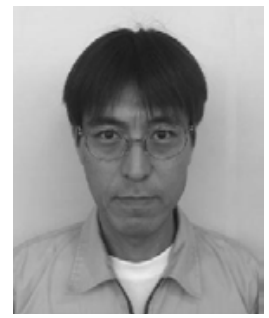

Yuji Miyazaki was born in Japan in 1968. He received the B. S. and M. S. degrees in electrical and computer engineering from the University of Kumamoto, Kumamoto, Japan, in 1991 and 1993, respectively. In 1993, he joined Toshiba Semiconductor Company. Since 2004, he has been working for Mitsubishi Electric Company, where he has been engaged in developing and manufacturing of power semiconductor devices. His research interests include $\mathrm{Si}$ and $\mathrm{SiC}$ power devices, and its reliability. 